\title{
Multiple campuses, one IACUC: how many AVs?
}

As Great Eastern University expanded to multiple campuses, so did its research base. Initially, there was the main campus, with one, then two and eventually four buildings with animal facilities. Ten years later came the northern campus, some 50 miles from the main campus. In eight more years, the western campus opened, nearly 200 miles from the main campus. Finally, the eastern campus came into being, 100 miles from the main campus. When the northern campus opened, the Attending Veterinarian (AV) initially was able to oversee animal activities at both campuses, but eventually, the northern campus hired its own veterinarian. When the two other campuses opened, they immediately required separate on-site veterinarians, although the AV for all the campuses continued to work at the main campus. In addition to one AV, Great Eastern also had a single IACUC, NIH/OLAW Assurance, USDA registration and Institutional Official for all campuses. Monthly IACUC meetings were held at the main campus.
Although having but one IACUC and one AV helped to provide a degree of consistency in animal care and use across the campuses, it became apparent that having the AV stationed at the main campus was not conducive to the smooth running of the other animal facilities. Each facility's veterinarian had many responsibilities but not all of the authority needed to facilitate the animal facility's operations. The overall authority for activities involving animals at Great Eastern University was still held by the AV. Therefore, a decision was made by the university's administration to have an AV at each of Great Eastern's four campuses. This decision was questioned by some IACUC members because they believed that the wording of the Animal Welfare Act regulations (AWARs) ${ }^{1}$, the Public Health Service Policy on Humane Care and Use of Laboratory Animals (PHS Policy) ${ }^{2}$ and the Guide for the Care and Use of Laboratory Animals ${ }^{3}$ all implied that there could be only one AV at Great Eastern. The IACUC members added that the four campuses were overseen by one university president and that there were certain university policies that affected all campuses. Taking all these factors together, they did not see anything allowing for more than one AV at Great Eastern. The chairperson of the IACUC said that the university administration would handle any issues that arose, but neither he nor the university's attorneys saw anything in the AWARs or the PHS Policy that prevented the university from having a separate AV at each campus.

What do you think? Can Great Eastern University have separate AVs at its different campuses, or do federal regulations and policy allow for just one $\mathrm{AV}$ at an institution having one IACUC and one Institutional Official?

1. Code of Federal Regulations, Title 9, Chapter 1, Subchapter A - Animal Welfare: Part 1 Definitions and Part 2 Regulations. $\$ 1.1$ $\S 2.31(b)(3)(i)$ and $\$ 2.33(a)(1-3)$.

2. Public Health Service. Policy on Humane Care and Use of Laboratory Animals (US Department of Health and Human Services, Washington, DC, 1986; amended 2002).

3. Institute for Laboratory Animal Research. Guide for the Care and Use of Laboratory Animals (National Academies Press, Washington, DC, 1996).

\section{RESPONSE}

\section{Acting AVs}

\section{Joyce K. Cohen, VMD \& Mark Sharpless, CMAR, CPIA}

The issues facing Great Eastern University as a result of having multiple site locations are a common challenge: many universities and facilities that operate physically separate animal units face similar dilemmas. Decisions regarding the care and use of animals at each facility cannot become compromised or complicated by the absence of a veterinarian on-site that has authority and decisionmaking abilities.

Section 2.33 of the Animal Welfare Act regulations (AWARs) ${ }^{1}$ states that each research facility shall hire or contract the services of an Attending Veterinarian (AV). The AV's duties are stated to include responsibility for providing adequate veterinary care, authority to ensure that the veterinary care and animal care programs are appropriate and being a voting member of the facility IACUC. Appointing an AV at each satellite facility will allow for adequate veterinary care and appropriate authority at each location. However, section 2.31 states specifically that an IACUC cannot include more than three members from the same unit. This could be a factor in Great Eastern's decision to name AVs at each of its separate facilities. The University may have to be cautious with the titles they use and designate the central facility veterinarian as Chief $\mathrm{AV}$ in order to comply with the AWARs as well as with the Public Health Service Policy on the Humane Care and Use of Laboratory Animals ${ }^{2}$. This
Policy states that the delegated veterinarian should "be a doctor of veterinary medicine with appropriate training or experience in laboratory animal science and medicine and who has direct or delegated program authority and responsibility for activities involving animals at the institution."

The Guide for the Care and Use of Laboratory Animals ${ }^{3}$ reiterates the duties of the AV as stated in the AWAR. Neither document specifically details that a facility must have a sole individual acting in the capacity of AV.

The individual filling the role of $\mathrm{AV}$ is designated by the Institutional Official and is charged with administrative oversight of the veterinary care program as well as the animal husbandry functions at all sites and facilities within the institution. The AV has the authority to allocate funds to ensure that 